\title{
Analysis and Design of a Compact Dual-Band Directional Antenna
}

\author{
XuLin Quan, RongLin Li, Senior Member, IEEE, YueHui Cui, and Manos M Tentzeris, Fellow, IEEE
}

\begin{abstract}
A new type of compact dual-band directional antenna is proposed for $2.4 / 5-G H z$ wireless access point and RFID reader applications. The dual-band antenna consists of a longer dipole for the lower band and a pair of shorter dipoles for the upper band. A simple coupling microstrip line is employed to excite the dipoles. Both the dual-band antenna and the feeding microstrip line are printed on the same substrate, leading to a fully planar structure. The length of the dipole for the lower band is shortened by a capacitive loading at each end of the dipole, offering a compact antenna configuration. The compact dual-band antenna achieves a desirable directional radiation pattern with an antenna gain of near $8 \mathrm{dBi}$ for the lower band and 9-10 dBi for the upper band. An equivalent circuit analysis for the design of the dual-band directional antenna is presented.
\end{abstract}

Index Terms-Directional antenna, dual-band antenna, RFID readers, wireless access points, wireless local area network (WLAN).

\section{INTRODUCTION}

$\mathbf{O}$ VER the past 10 years, a lot of dual-band antennas have been developed for wireless communications, particularly for $2.4 / 5-\mathrm{GHz}$ wireless local area networks (WLANs) applications [1]-[14]. However, most of these dual-band antennas have an omnidirectional radiation pattern, which is most suitable for mobile terminals, such as cellular phones or laptop computers. For indoor wireless access points (APs) or point-to-point communications, it is sometimes required that the radiation pattern is directional to allow mounting the antenna against a wall or a ceiling surface [15], [16]. Recently, RFID reader antennas operating at $2.4 / 5-\mathrm{GHz}$ ISM bands are also required to have a high-gain directional pattern [17], [18]. It is desirable for the antennas mounted on a wall/ceiling surface to be compact and low-profile. A number of dual-band directional antennas have been investigated in recent years. Nevertheless, these dual-band directional antenna structures either have a stacked configuration [19]-[23] or a high profile [24].

In this letter, we propose a new simple compact planar dual-band directional antenna. The dual-band antenna consists

Manuscript received April 20, 2012; accepted May 07, 2012. Date of publication May 15, 2012; date of current version May 24, 2012. This work was supported by the National Natural Science Foundation of China under Grant 60871061, the Guangdong Province Natural Science Foundation under Grant 8151064101000085 , and the Specialized Research Fund for the Doctoral Program of Higher Education under Grant 20080561.

X. Quan, R. Li, and Y. Cui are with the School of Electronic and Information Engineering, South China University of Technology, Guangzhou 510641, China (e-mail: lirl@scut.edu.cn).

M. M. Tentzeris is with the School of Electrical and Computer Engineering, Georgia Institute of Technology, Atlanta, GA 30332 USA.

Color versions of one or more of the figures in this letter are available online at http://ieeexplore.ieee.org.

Digital Object Identifier 10.1109/LAWP.2012.2199458

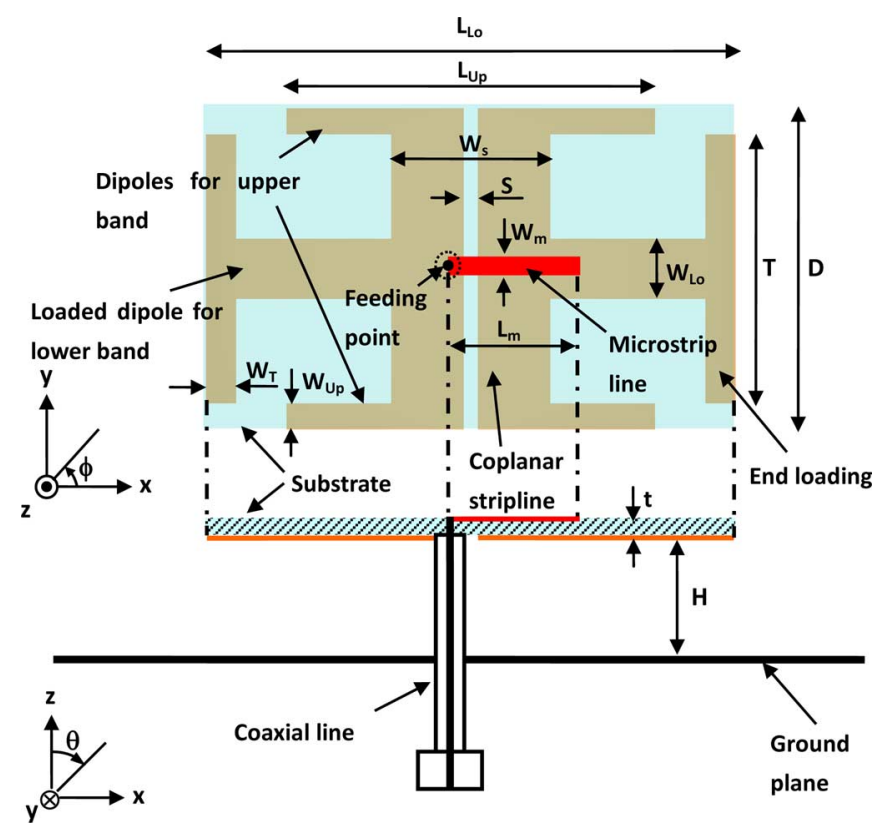

Fig. 1. Configuration of a compact dual-band directional antenna.

of a single dipole for the lower band and a pair of dipoles for the upper band. All of these dipoles are printed on the same substrate and excited by a simple coupling microstrip line. The compactness of the dual-band antenna is achieved by end-loading the dipole for the lower band with a pair of capacitive strip lines. The compact dual-band antenna has a desirable directional radiation pattern in both the lower band and the upper band with antenna gains of $\sim 8$ and $9-10 \mathrm{dBi}$, respectively. An equivalent circuit analysis for the design of the dual-band directional antennas is presented with experimental verification.

\section{ANTENNA CONFIGURATION}

The configuration of a compact dual-band directional antenna is depicted in Fig. 1. The dual-band antenna consists of a longer dipole and a pair of shorter dipoles, which are designed for operation at the 2.4-GHz ISM band (2.4-2.5 GHz) and the 5-GHz UNII band (5.1-5.9 GHz), respectively. The pair of shorter dipoles for the upper band is connected by a coplanar stripline. All dipoles are printed on the bottom side of a thin RT/Duroid 5880 substrate (dielectric constant $\varepsilon_{\mathrm{r}}=2.2$, loss tangent $=0.0009$, and thickness $t=0.5 \mathrm{~mm}$ ). The printed dipoles are placed above a ground plane $\left(100 \times 60 \mathrm{~mm}^{2}\right)$ and excited by a coupling microstrip line across the coplanar strip. The coupling microstrip line is printed on the top side of the 


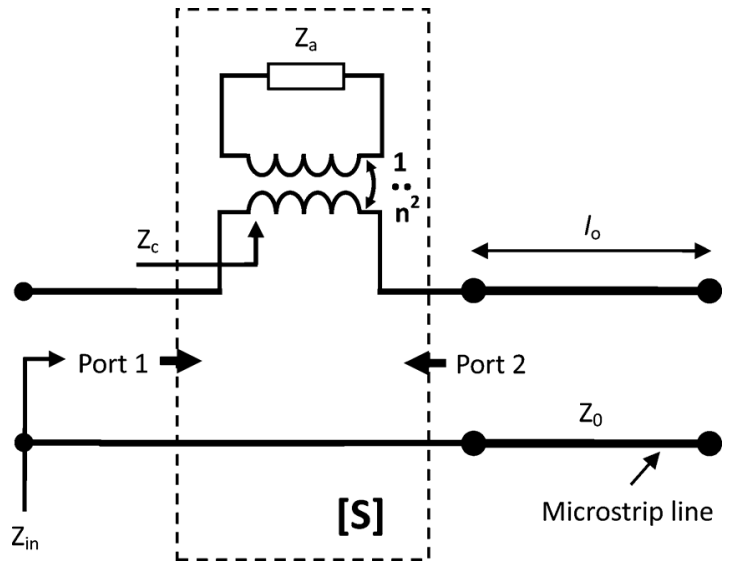

Fig. 2. Equivalent circuit for the coupling feed $\left(l_{\mathrm{o}} \cong L_{\mathrm{m}}-S\right)$.

TABLE I

GeOMETRIC Parameters For the COMPaCt DuAL-BAND DIRECTIONAL ANTENNA

\begin{tabular}{|c|c|c|c|}
\hline Parameter & Value & Parameter & Value \\
\hline $\mathrm{L}_{\mathrm{L} 0}$ & $43 \mathrm{~mm}$ & $\mathrm{~W}_{\mathrm{s}}$ & $13 \mathrm{~mm}$ \\
\hline $\mathrm{L}_{\mathrm{Up}_{\mathrm{p}}}$ & $30 \mathrm{~mm}$ & $\mathrm{~S}$ & $1 \mathrm{~mm}$ \\
\hline $\mathrm{L}_{\mathrm{m}}$ & $10.5 \mathrm{~mm}$ & $\mathrm{~W}_{\mathrm{m}}$ & $1.5 \mathrm{~mm}$ \\
\hline $\mathrm{D}$ & $26 \mathrm{~mm}$ & $\mathrm{~W}_{\mathrm{L} 0}$ & $5 \mathrm{~mm}$ \\
\hline $\mathrm{T}$ & $22 \mathrm{~mm}$ & $\mathrm{~W}_{\mathrm{Up}}$ & $2 \mathrm{~mm}$ \\
\hline $\mathrm{H}$ & $12 \mathrm{~mm}$ & $\mathrm{~W}_{\mathrm{T}}$ & $2.5 \mathrm{~mm}$ \\
\hline $\mathrm{t}$ & $0.5 \mathrm{~mm}$ & & \\
\hline
\end{tabular}

substrate and fed through a 0.084 -in semi-rigid coaxial line at the inner side of the coplanar strip.

To make the dual-band directional antenna compact, the length of the dipole for the $2.4-\mathrm{GHz}$ band is shortened by introducing a pair of capacitive loadings (i.e., a pair of parallel strip lines) at the ends of the dipole. The total size of the dual-band directional antenna is $43 \times 26 \times 12 \mathrm{~mm}^{3}$, comparable to that $\left(40 \times 32.5 \times 8 \mathrm{~mm}^{3}\right)$ for a $2.4 / 5.8-\mathrm{GHz}$ dual-band directional antenna proposed in [17], but much more compact than that $\left(57 \times 57 \times 21 \mathrm{~mm}^{3}\right)$ for a $2.5-4.8 \mathrm{GHz}$ wideband slot antenna presented in [16]. It should be mentioned that even though the dual-band directional antenna proposed in [17] has a lower height, it consists of a stacked configuration, and its operating frequency at the $5-\mathrm{GHz}$ band only covers the $5.8-\mathrm{GHz}$ ISM band $(5.725-5.875 \mathrm{GHz})$. Therefore, the dual-band directional antenna proposed in this letter has the advantage of simple structure and relatively wide bandwidth. All geometric parameters for the compact dual-band directional antenna are listed in Table I.

\section{EQuivalent Circuit ANAlysis}

To understand the impedance matching for the coupling feed, an equivalent circuit model is presented in Fig. 2. The input impedance of the dual-band antenna as excited by a voltage source (the coupling microstrip line has not been introduced yet) is denoted by $Z_{\mathrm{a}}$. The coupling between the coplanar stripline and the microstrip line can be represented as an ideal transformer that has a turn ratio of $n$. Following the transformer, the impedance $Z_{\mathrm{a}}$ is transformed into $Z_{\mathrm{c}}$

$$
Z_{\mathrm{c}}=n^{2} Z_{\mathrm{a}}
$$

where $n^{2}$ is called the impedance transformer coefficient. The input impedance $\left(Z_{\text {in }}\right)$ looking into the microstrip line at the feed point is obtained by taking into account the opened microstrip line, which gives

$$
Z_{\text {in }}=Z_{\mathrm{c}}-\mathrm{j} Z_{0} \cot \beta_{0} l_{\mathrm{o}}
$$

where $Z_{0}, \beta_{0}$, and $l_{\mathrm{o}}$ are the characteristic impedance, phase constant, and the length of the opened microstrip line, respectively.

Since it is difficult to calculate the impedance transformer coefficient $n^{2}$, we obtain $Z_{\mathrm{c}}$ by exciting the dual-band antenna with a two-port microstrip line across the coplanar stripline. Then, $Z_{\mathrm{c}}$ is determined from the $S$-parameters of the two-port network enclosed in Fig. 2, which can be expressed as [25]

$$
Z_{\mathrm{c}}=Z_{0} \frac{\left(1+S_{11}\right)\left(1+S_{22}\right)-S_{12} S_{21}}{2 S_{21}} .
$$

The results for $Z_{\mathrm{a}}$ and $Z_{\mathrm{c}}$ are given in a Smith chart as shown in Fig. 3. We can see that $Z_{\mathrm{a}}$ is far away from the center of the Smith chart for the lower band and close to the SWR = 2:1 circle for the upper band, which means a bad impedance matching for the lower band and a slightly better impedance matching for the upper band. Following the transformer, the impedance $Z_{\mathrm{a}}$ is transformed into $Z_{\mathrm{c}}$. For the lower band, $Z_{\mathrm{c}}$ is still outside the SWR $=2: 1$ circle. However, for the upper band, $Z_{\mathrm{c}}$ has moved to the inside of the SWR $=2: 1$ circle. After the introduction of the coupling microstrip line, we obtain the input impedance $Z_{\text {in }}$ from (2). From Fig. 3, we can see that $Z_{\text {in }}$ for the lower band has gotten to the inside of the SWR $=2: 1$ circle, thus good impedance matching is achieved. For the upper band, $Z_{\text {in }}$ still remains inside the $\mathrm{SWR}=2: 1$ circle.

From the above analysis, we have the following guidelines for the design of the dual-band directional antenna.

1) The impedance matching for the lower band is dominated by the impedance $Z_{\mathrm{a}}$ and the length of the microstrip line. The coplanar stripline is less important.

2) The impedance matching for the upper band is determined by the impedance $Z_{\mathrm{a}}$ and the coplanar stripline. The length of the microstrip line is less important.

The input impedance $Z_{\text {in }}$ calculated using (2) is compared to simulation results in Fig. 3. It can be seen that the calculated and simulated results are in good agreement, thus validating the equivalent circuit analysis.

\section{EXPERIMENTAL RESULTS}

Measured input impedance is marked in Fig. 3. Agreement is observed. Slight difference is due to the effect of the feeding coaxial line, which causes some calibration error. Measured return loss is compared to simulation results in Fig. 4. The 10-dB return loss bandwidths are $2.39-2.51 \mathrm{GHz}$ for the $2.4-\mathrm{GHz}$ band and $4.4-6.5 \mathrm{GHz}$ for the 5-GHz band, respectively. Note that there is a spurious resonance around $1.4 \mathrm{GHz}$. This resonance is due to the feeding coaxial line that forms a top-loaded monopole with the dual-band antenna. The omnidirectional radiation pattern at $1.4 \mathrm{GHz}$ (see the inset of Fig. 4) confirms the monopole mode. Note that the coaxial line has little effect on the directional radiation patterns for the 2.4- and 5-GHz bands. Radiation patterns measured and simulated at 2.45 and $5.5 \mathrm{GHz}$ are plotted 


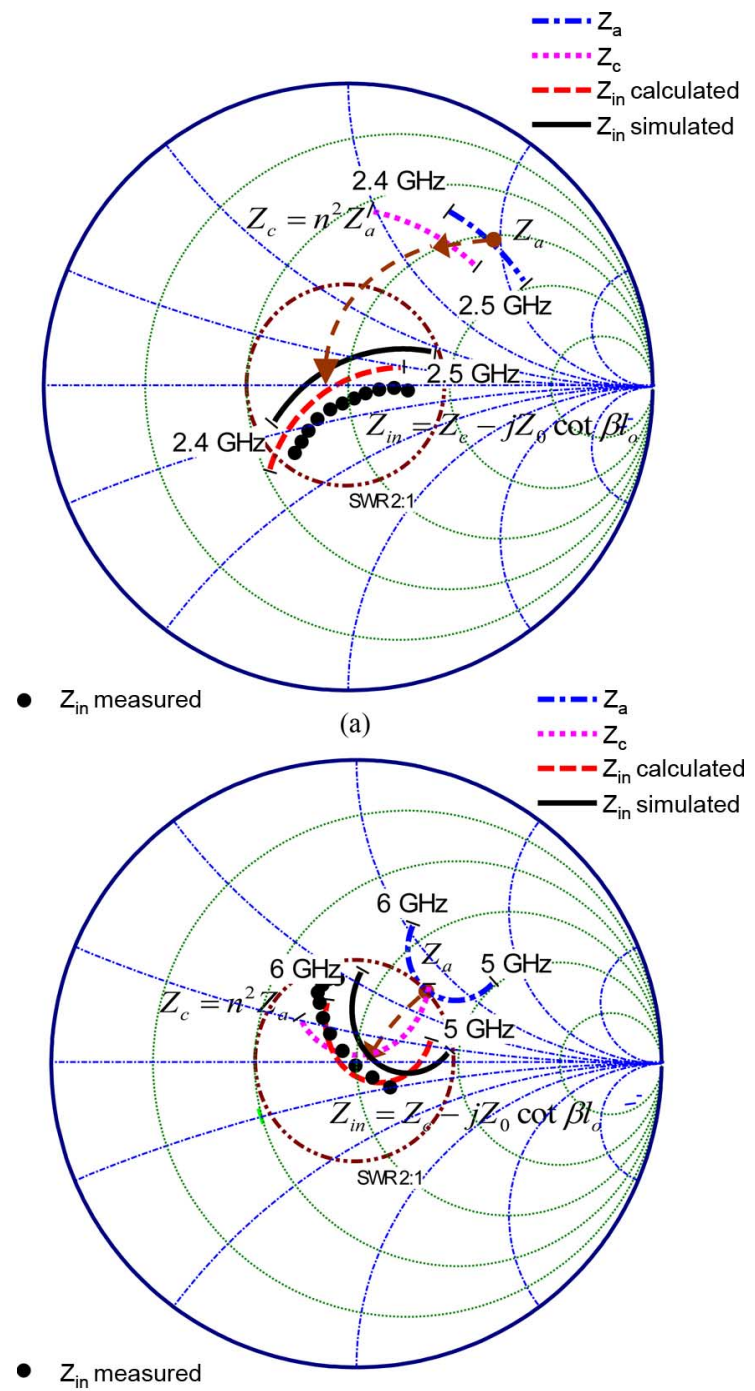

(b)

Fig. 3. Impedance matching of the compact dual-band directional antenna. (a) 2.4-GHz band. (b) 5-GHz band.

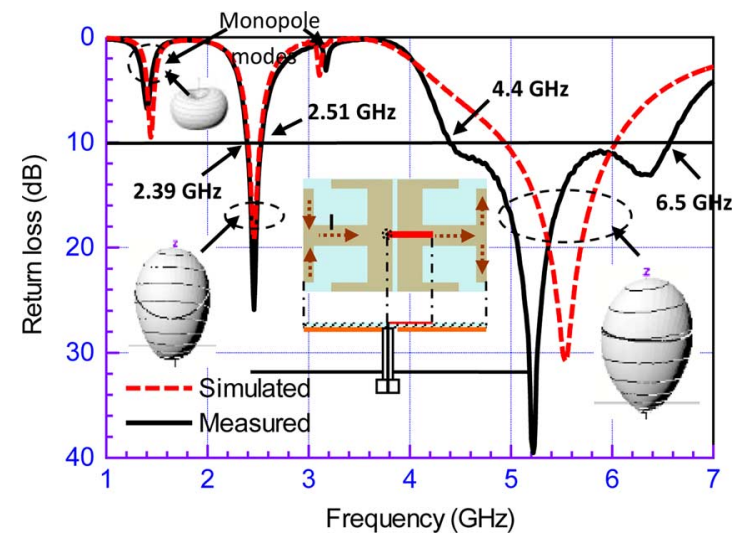

Fig. 4. Return loss of the compact dual-band directional antenna (insets are the 3 -D radiation patterns at resonances).

in Fig. 5. Good directional radiation patterns are observed for both frequencies. Cross-polarization level is more than $20 \mathrm{~dB}$ lower than the copolarization, much better than that $(\sim 10 \mathrm{~dB})$ obtained in [17]. It should be mentioned that the end-loading
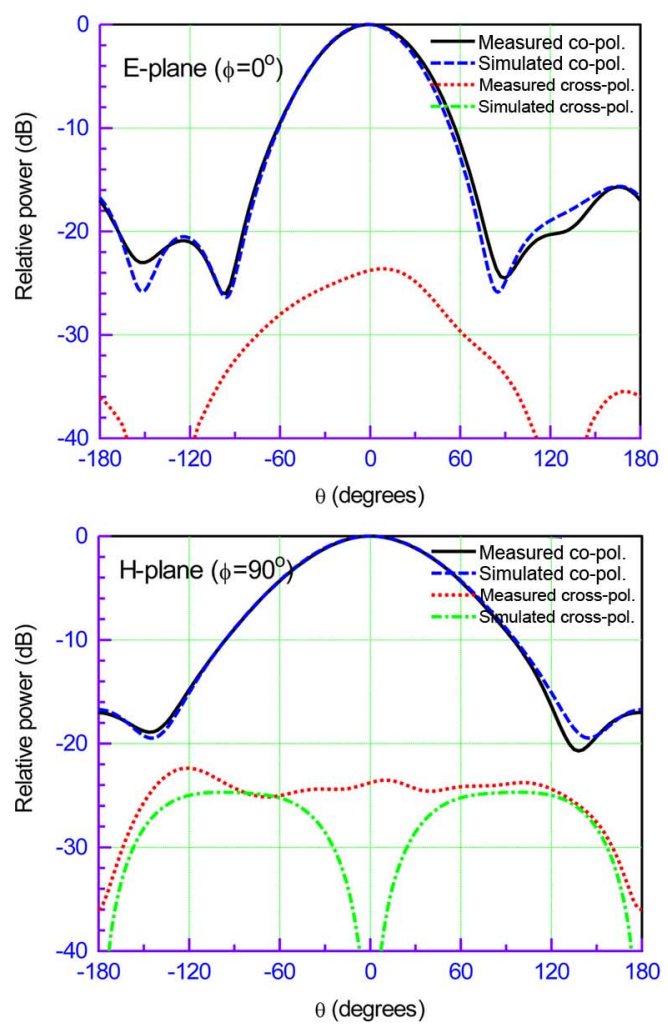

(a)
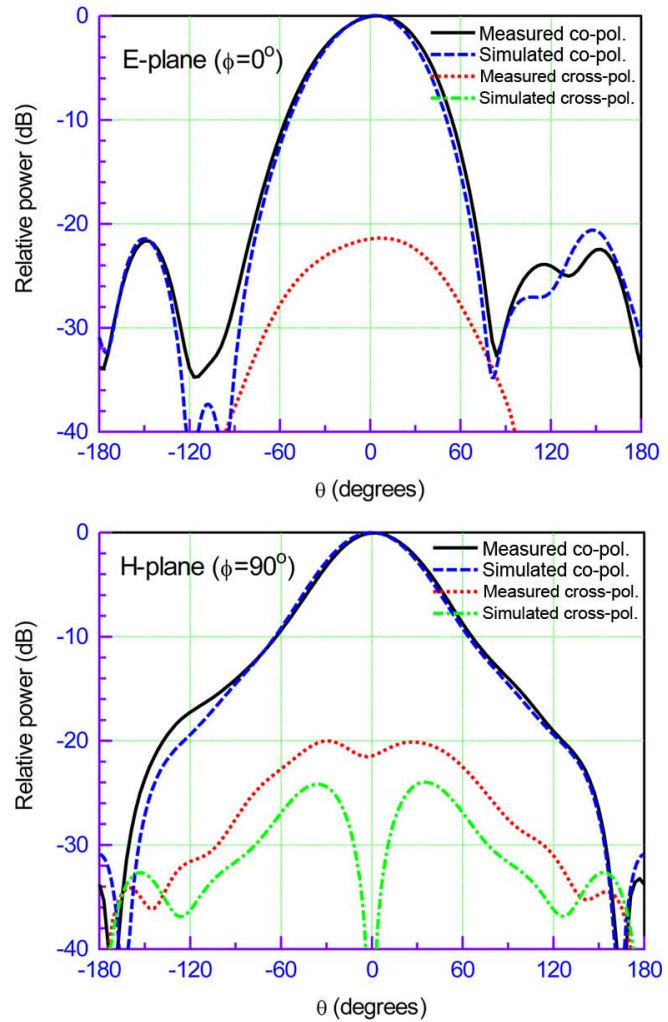

(b)

Fig. 5. Radiation patterns of the compact dual-band directional antenna at (a) 2.45 and (b) $5.5 \mathrm{GHz}$.

strips have little effect on the radiation pattern because the current on each strip flows in the two opposite directions, resulting in a cancellation for the far field. The antenna gains for the 


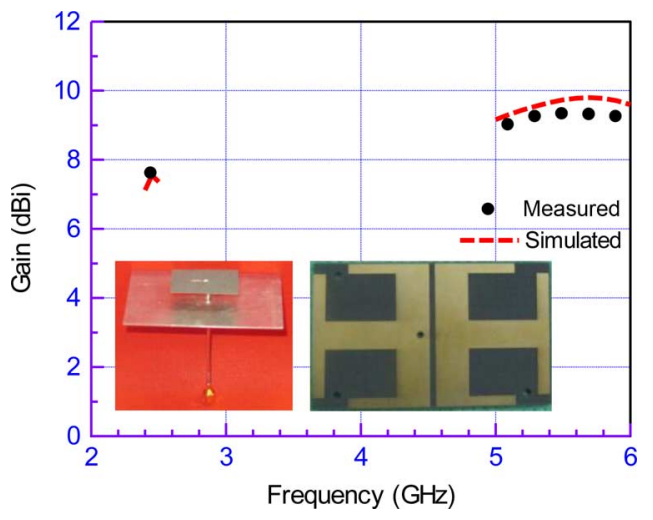

Fig. 6. Gain of the compact dual-band directional antenna (inset is the antenna prototype).

compact dual-band directional antenna are respectively about $7.5 \mathrm{dBi}$ for the 2.4-GHz band and $9.5 \mathrm{dBi}$ for the $5-\mathrm{GHz}$ band as shown in Fig. 6, comparable to those in [17]. The higher gain in the upper band is due to the configuration of a two-dipole array. The higher-gain characteristic in the upper band is desirable for wireless communications because radio signals experience a higher path loss at a higher frequency. The radiation efficiency is higher than $95 \%$, suitable for energy-efficient wireless access point and RFID reader applications.

\section{CONCLUSION}

A new type of compact dual-band directional antenna has been proposed and analyzed. The dual-band antenna consists of a capacitively loaded single dipole for the lower band and a two-dipole array for the upper band. All dipoles are printed on the same thin substrate. The printed dipole antenna is excited by a simple coupling microstrip line. The compact dual-band directional antenna achieves a desirable directional radiation pattern with a gain of $\sim 8 \mathrm{dBi}$ for the $2.4-\mathrm{GHz}$ band and $9-10 \mathrm{dBi}$ for the $5-\mathrm{GHz}$ band. Thus, it may find applications in wireless access points for high-speed WLANs or in RFID readers for long-range detection.

\section{ACKNOWLEDGMENT}

The authors would like to thank SATIMO, Atlanta, GA, for radiation pattern measurement.

\section{REFERENCES}

[1] Y.-L. Kuo and K.-L. Wong, "Printed double-T monopole antenna for 2.4/5.2 GHz dual-band WLAN operations," IEEE Trans. Antennas Propag., vol. 51, no. 9, pp. 2187-2192, Sep. 2003.

[2] J.-Y. Jan and L.-C. Tseng, "Small planar monopole antenna with a shorted parasitic inverted-L wire for wireless communications in the 2.4, 5.2, and 5.8-GHz bands," IEEE Trans. Antennas Propag., vol. 52, no. 7, pp. 1903-1905, Jul. 2004.

[3] K.-L. Wong, L.-C. Chou, and C.-M. Su, "Dual-band flat-plate antenna with a shorted parasitic element for laptop applications," IEEE Trans. Antennas Propag., vol. 53, no. 1, pp. 539-544, Jan. 2005.
[4] S.-B. Chen, Y.-C. Jiao, W. Wang, and F.-S. Zhang, "Modified T-shaped planar monopole antennas for multiband operation," IEEE Trans. Microw. Theory Tech., vol. 54, no. 8, pp. 3267-3270, Aug. 2006.

[5] L.-C. Chou and K.-L. Wong, "Uni-planar dual-band monopole antenna for 2.4/5 GHz WLAN operation in the laptop computer," IEEE Trans. Antennas Propag., vol. 55, no. 12, pp. 3739-3741, Dec. 2007.

[6] X.-C. Lin and C.-C. Yu, "A dual-band CPW-fed inductive slot-monopole hybrid antenna," IEEE Trans. Antennas Propag., vol. 56, no. 1, pp. 282-285, Jan. 2008.

[7] P. Callaghan and J. C. Batchelor, "Dual-band pin-patch antenna for Wi-Fi applications," IEEE Antennas Wireless Propag. Lett., vol. 7, pp. 57-760, 2008.

[8] S.-J. Lin and J.-S. Row, "Monopolar patch antenna with dual-band and wideband operations," IEEE Trans. Antennas Propag., vol. 56, no. 3, pp. 900-903, Mar. 2008.

[9] H. Zhang and H. Xin, "A dual-band dipole antenna with integratedbalun," IEEE Trans. Antennas Propag., vol. 57, no. 3, pp. 786-789, Mar. 2009.

[10] L. Lizzi, F. Viani, and A. Massa, "Dual-band spline-shaped PCB antenna for Wi-Fi applications," IEEE Antennas Wireless Propag. Lett., vol. 8, pp. 616-619, 2009.

[11] M. Midrio, S. Boscolo, F. Sacchetto, C. G. Someda, A. D. Capobianco, and F. M. Pigozzo, "Planar, compact dual-band antenna for wireless LAN applications," IEEE Antennas Wireless Propag. Lett., vol. 8, pp. 1234-1237, 2009.

[12] T. N. Chang and J.-H. Jiang, "Meandered T-shaped monopole antenna," IEEE Trans. Antennas Propag., vol. 57, no. 12, pp. 3976-3978, Dec. 2009.

[13] Q.-X. Chu and L.-H. Ye, "Design of compact dual-wideband antenna with assembled monopoles," IEEE Trans. Antennas Propag., vol. 58, no. 12, pp. 4063-4066, Dec. 2010.

[14] Y.-C. Chen, S.-Y. Chen, and P. Hsu, "Modification of radiation patterns of first harmonic mode of slot dipole for dual-frequency operation," IEEE Trans. Antennas Propag., vol. 59, no. 7, pp. 2707-2710, Jul. 2011.

[15] R. Gardelli, G. La Cono, and M. Albani, "A low-cost suspended patch antenna for WLAN access points and point-to-point links," IEEE Antennas Wireless Propag. Lett., vol. 3, pp. 90-93, 2004.

[16] C. R. Medeiros, E. B. Lima, J. R. Costa, and C. A. Fernandes, "Wideband slot antenna for WLAN access points," IEEE Antennas Wireless Propag. Lett., vol. 9, pp. 79-82, 2010.

[17] A. T. Mobashsher, M. T. Islam, and N. Misran, "A novel high-gain dual-band antenna for RFID reader applications," IEEE Antennas Wireless Propag. Lett., vol. 9, pp. 653-656, 2010.

[18] M. I. Sabran, S. K. A. Rahim, A. Y. A. Rahman, T. A. Rahman, M. Z. M. Nor, and Evizal, "A dual-band diamond-shaped antenna for RFID application,” IEEE Antennas Wireless Propag. Lett., vol. 10, pp. 979-982, 2011.

[19] J.-H. Lu, "Broadband dual-Frequency operation of circular patch antennas and arrays with a pair of L-shaped slots," IEEE Trans. Antennas Propag., vol. 51, no. 5, pp. 1018-1023, May 2003.

[20] K. Oh, B. Kim, and J. Choi, "Design of dual and wideband aperture stacked patch antenna with double-sided notches," Electron. Lett., vol. 40, no. 11, pp. 643-645, 2004.

[21] P. Li, K. M. Luk, and K. L. Lau, "A dual-feed dual-band L-probe patch antenna," IEEE Trans. Antennas Propag., vol. 53, no. 7, pp. 2321-2323, Jul. 2005.

[22] M. N. Mahmoud and R. Baktur, "A dual band microstrip-fed slot antenna," IEEE Trans. Antennas Propag., vol. 59, no. 5, pp. 1720-1724, May 2011.

[23] X. S. Fang and K. W. Leung, "Designs of single-, dual-, wide-band rectangular dielectric resonator antennas," IEEE Trans. Antennas Propag., vol. 59, no. 6, pp. 2409-2414, Jun. 2011.

[24] F. Tefiku and C. A. Grimes, "Design of broad-band and dual-band antennas comprised of series-fed printed-strip dipole pairs," IEEE Trans. Antennas Propag., vol. 48, no. 6, pp. 895-900, Jun. 2000.

[25] D. M. Pozar, Microwave Engineering, 2nd ed. New York: Wiley, 1998, p. 211. 